\title{
Variation in leaf anatomical characteristics in chromosomal segment substitution lines of KDML105 carrying drought tolerant QTL segments
}

\author{
Charanya Kulya ${ }^{\mathrm{a}}$, Jonaliza L. Siangliw ${ }^{\mathrm{b}}$, Theerayut Toojinda ${ }^{\mathrm{b}}$, Watanachai Lontom ${ }^{\mathrm{a}}$, \\ Wattana Pattanagul $^{\mathrm{a}}$, Narasak Sriyot ${ }^{\mathrm{a}}$, Jirawat Sanitchon ${ }^{\mathrm{c}}$, Piyada Theerakulpisut ${ }^{\mathrm{a}, *}$ \\ a Salt-tolerant Rice Research Group, Department of Biology, Faculty of Science, Khon Kaen University, \\ Khon Kaen 40002 Thailand \\ b Rice Gene Discovery Unit, National Centre for Genetic Engineering and Biotechnology, \\ Kasetsart University, Kamphangsaen, Nakhon Pathom 73140 Thailand \\ c Department of Plant Science and Agricultural Resources, Faculty of Agriculture, Khon Kaen University, \\ Khon Kaen 40002 Thailand
}

*Corresponding author, e-mail: piythe@kku.ac.th

Received 21 Dec 2017

Accepted 4 Jun 2018

\begin{abstract}
We examined quantitative traits in leaf anatomical characteristics in 20 chromosomal segment substitution lines (CSSLs) of rice cultivar Khao Dawk Mali 105 (KDML105) carrying drought-tolerant quantitative trait loci (DT-QTL) segments from drought-tolerant donors. Two DT-QTL donor lines DH103 and DH212, drought-sensitive recurrent parent KDML105, and two drought-tolerant standard checks CT9993 and IR62266 (parental lines of DH103 and DH212) were also included for comparison. A total of 20 quantitative leaf anatomical characters were evaluated from fully expanded leaves of greenhouse-grown 30-day-old plants. The results showed that the studied rice lines displayed variations in their leaf dimensions, with the four drought-tolerant lines and almost all 20 CSSLs exhibiting wider leaves, higher number of small and total vascular bundles, higher stomatal density, and shorter stomatal length than those of KDML105. Eleven out of 20 characters were selected for principal component analysis and the studied lines were categorized into 7 groups, with the drought-tolerant standard check CT9993 clearly isolated from the others due to its outstanding characters. CSSL-9, which shared major similarities of quantitative traits to CT9993, fell outside its CSSL group. The characters related to drought tolerance ability were shared between the improved CSSL lines and the drought-tolerant lines, but differed from KDML105 and included the wider leaves, the higher number of small and total vascular bundles, and denser but smaller stomata.
\end{abstract}

KEYWORDS: leaf anatomy, vascular bundles, stomatal density, Oryza sativa

\section{INTRODUCTION}

Severe droughts are observed almost every year in rainfed crop-growing areas in many parts of the world, including the northeastern region of Thailand ${ }^{1}$. The major consequences of drought in crop plants include a reduced rate of cell division and expansion, leaf size, stem elongation and root proliferation, and disturbed stomatal oscillations, plant water and nutrient relations with diminished crop productivity, and water use efficiency ${ }^{2}$.

Crop plants adapt to drought via physiological, biochemical, morphological and molecular adjustments. Because plant water uptake is a complex process which depends on the structure and anatomy of vascular bundles ${ }^{3}$, crop plants with different drought tolerance might have differentially evolved the structure and anatomy of their vascular bundles and other relevant anatomical features. Hence investigating variations in the anatomical features of crop plants differing in their tolerance to drought stress is of great importance. Additionally, as compared to other traits, anatomical characteristics can be efficiently used as an indicator of drought tolerance as they are less susceptible to environmental change ${ }^{4}$. Besides, it is well-documented that drought stimulates subtle variations in biochemical and physiological processes ${ }^{5}$ and therefore, these traits are less likely to give obvious clues for discriminating differences in drought tolerance of crop plants.

Many recent studies have examined the physio- 
logical and morphological characteristics in various crop plants with different drought tolerance ${ }^{6}$. However, few studies have investigated the anatomical variations in crop plants differing in their tolerance to drought stress with the emphasis on the size, area and total number of vascular bundles ${ }^{7}$ even though vascular bundles are well-documented to affect plant water uptake ${ }^{8}$. According to this, variations in vascular bundles should be studied in addition to other anatomical features in crop plants with different resistance to drought, to make the anatomical characteristics a reliable indicator of drought tolerance ${ }^{9}$.

Rice (Oryza sativa) is one of the most economically important cereal crops, accounting for about one-fifth of the total caloric intake of the human population worldwide ${ }^{1}$. Rice is highly susceptible to drought stress throughout its life cycle ${ }^{10}$, with huge economic losses or even complete crop failures observed during the flowering stage. Improvement of rice productivity under water-limiting conditions is therefore of great importance for food security of the growing global population ${ }^{11}$.

Thailand remains one of the world's top rice producers which consistently ranks in the top 10 nations worldwide for output and is the largest single exporter. Rice cultivation is highly decentralized throughout the country with major growing regions focused in the lower north, central plains and the northeast. Thai Jasmine rice cultivar Khao Dawk Mali 105 (KDML105) is planted as majority in the northeast of Thailand ${ }^{1}$ because of its unique fragrance and premium cooking quality. Since KDML105 is drought-prone, its production in the northeastern part of Thailand is severely affected every year as a result of reduced rainfall. The development of chromosome segment substitution lines (CSSLs) of KDML105 with quantitative trait loci (QTL) associated with drought tolerance (DT) is one of the strategies to improve drought tolerance in this rice cultivar. The obtained CSSLs have been shown to have higher mean values of grain yields as compared to KDML105 under drought and irrigated conditions ${ }^{12}$. Because rice leaves have been documented to be associated with photosynthesis and grain yield, identifying the anatomical characteristics of CSSLs differing in their tolerance to drought should facilitate the selection of promising characteristics to be used as an indicator of drought tolerance.

This study was carried out to examine the leaf anatomical traits in 20 CSSLs of KDML105 carrying DT-QTLs on chromosomes $1,3,4,8$, and 9. These
CSSLs were selected from 139 CSSLs differing in their tolerance to drought as indicated by field experiments from an earlier study ${ }^{12}$. In this context, the parent line KDML105, the QTL donors DH102 and DH103, and drought-tolerant standard check cultivars IR62266 and CT9993 were included in the study.

\section{MATERIALS AND METHODS}

\section{Plant materials and growing}

A total of 25 genotypes were investigated including 20 CSSLs of KDML105 which received DT-QTLs from chromosome 1 (CSSL 1-4), 3 (CSSL 5-8), 4 (CSSL 912), 8 (CSSL 13-16), and 9 (CSSL 17-20) of the QTL donor parents DH212 (chromosomes 1, 3, 4, and 9) and DH103 (chromosome 8), 2 drought-resistant QTL donors (DH212 and DH103), 2 standard checks (IR62266 and CT9993) and KDML105 (the recurrent parent) (Table 1). All rice seeds were provided by Rice Gene Discovery Unit, National Centre for Genetic Engineering and Biotechnology. These CSSLs had been developed by marker-assisted backcrossing between KDML105 as the recipient parent and two DT-QTL donors, IR58586-F2-CA-143 (DH212) and IR58586-F2-CA-31 (DH103) as male parents by Siangliw et $\mathrm{al}^{13}$ and Kanjoo et $\mathrm{al}^{14}$. The two donors were derived from a cross between CT9993 and IR62266. These donors carried CT9993 alleles at the QTL locations on chromosomes 1, 3, 4 and 9, and IR62266 alleles on chromosome 8. The development of $\mathrm{F}_{1}$ to $\mathrm{BC}_{3} \mathrm{~F}_{1}$ was carried out by Siangliw et $\mathrm{al}^{13}$. The continued backcrossing was conducted by Kanjoo et al ${ }^{14}$ until $\mathrm{BC}_{5} \mathrm{~F}_{1}$ generations.

Seeds of the 20 CSSLs, DH212, DH103, KDML105, IR62266 and CT9993 were surfacesterilized in $7 \%$ sodium hypochlorite and washed several times with distilled water. Seeds were then germinated on filter papers and germinated seedlings were transferred to PVC pots $(10 \mathrm{~cm}$ in diameter $\times 50 \mathrm{~cm}$ in height) filled with $4 \mathrm{~kg}$ of sandy loam soil (previously crushed and sieved through 2$\mathrm{mm}$ metal strain) to the depth of $40 \mathrm{~cm}$. The soil was wetted with tap water to field capacity. Five pots were set up for each line and arranged in completely randomized design inside a concrete pond $\left(4 \times 0.8 \times 0.7 \mathrm{~m}^{3}\right)$ in a net house $\left(12 \times 8 \mathrm{~m}^{2}\right)$ located at the Crop Station of the Faculty of Agriculture of Khon Kaen University. The pond was irrigated with tap water to the level $5 \mathrm{~cm}$ above the soil when the seedlings were 14-day old and well-established. The 30-day-old rice plants were harvested for quantitative analysis of leaf anatomical characteristics. 
Table 1 Lists of CSSLs and checked lines used in this study.

\begin{tabular}{|c|c|c|c|c|}
\hline Entry & Crossing & Pedigree & Chromosome & Remark \\
\hline CSSL-1 & KDML105*6/IR68586-F2-CA-143 & RGD05164-11-MAS39 & 1 & Donor DH212 \\
\hline CSSL-2 & KDML105*6/IR68586-F2-CA-143 & RGD05164-11-MAS25 & 1 & Donor DH212 \\
\hline CSSL-3 & KDML105*6/IR68586-F2-CA-143 & RGD05164-23-MAS10 & 1 & Donor DH212 \\
\hline CSSL-4 & KDML105*6/IR68586-F2-CA-143 & RGD05164-26-MAS18 & 1 & Donor DH212 \\
\hline CSSL-5 & KDML105*6/IR68586-F2-CA-143 & RGD05169-2-MAS12 & 3 & Donor DH212 \\
\hline CSSL-6 & KDML105*6/IR68586-F2-CA-143 & RGD05162-3-MAS56 & 3 & Donor DH212 \\
\hline CSSL-7 & KDML105*6/IR68586-F2-CA-143 & RGD05162-3-MAS44 & 3 & Donor DH212 \\
\hline CSSL-8 & KDML105*6/IR68586-F2-CA-143 & RGD05162-8-MAS41 & 3 & Donor DH212 \\
\hline CSSL-9 & KDML105*6/IR68586-F2-CA-143 & RGD05131-4-MAS39 & 4 & Donor DH212 \\
\hline CSSL-10 & KDML105*6/IR68586-F2-CA-143 & RGD05131-6-MAS5 & 4 & Donor DH212 \\
\hline CSSL-11 & KDML105*6/IR68586-F2-CA-143 & RGD05128-10-MAS12 & 4 & Donor DH212 \\
\hline CSSL-12 & KDML105*6/IR68586-F2-CA-143 & RGD05128-4-MAS40-MAS11 & 4 & Donor DH212 \\
\hline CSSL-13 & KDML105*6/IR68586-F2-CA-31 & RGD06063-69-MAS24 & 8 & Donor DH103 \\
\hline CSSL-14 & KDML105*6/IR68586-F2-CA-31 & RGD06064-6-MAS52 & 8 & Donor DH103 \\
\hline CSSL-15 & KDML105*6/IR68586-F2-CA-31 & RGD06064-6-MAS16-MAS2 & 8 & Donor DH103 \\
\hline CSSL-16 & KDML105*6/IR68586-F2-CA-31 & RGD06064-26-MAS45-MAS8 & 8 & Donor DH103 \\
\hline CSSL-17 & KDML105*6/IR68586-F2-CA-143 & RGD05160-6-MAS29 & 9 & Donor DH212 \\
\hline CSSL-18 & KDML105*6/IR68586-F2-CA-143 & RGD05157-5-MAS8 & 9 & Donor DH212 \\
\hline CSSL-19 & KDML105*6/IR68586-F2-CA-143 & RGD05159-4-MAS56 & 9 & Donor DH212 \\
\hline CSSL-20 & KDML105*6/IR68586-F2-CA-143 & RGD05159-4-MAS52-MAS4 & 9 & Donor DH212 \\
\hline KDML105 & KDML105 & KDML105 & Parent & \\
\hline DH103 & DH103 & DH103 & Parent & \\
\hline DH212 & DH212 & DH212 & Parent & \\
\hline IR62266 & IR62266 & IR62266 & Standard check & Lowland rice \\
\hline СТ9993 & СТ9993 & СТ9993 & Standard check & Upland rice \\
\hline
\end{tabular}

\section{Quantifying leaf anatomical characteristics}

For each line, five fully expanded leaves were harvested from five individual 30-day-old plants; one from each pot, and fixed in $70 \%$ alcohol. A segment of leaf blade approximately $0.5 \mathrm{~cm}$ in length from the middle zone was dehydrated, infiltrated, embedded in paraffin and subjected to a crosssectional process (modified from Ref. 15) using a sliding microtome (model Leica SM 2000R, Leica Microsystems, Nussloch, Germany). Transverse sections of $10 \mu \mathrm{m}$ thickness were stained with $1 \%$ safranin $\mathrm{O}$ in $70 \%$ ethanol for $24 \mathrm{~h}$. Following staining, sections were rinsed with distilled water and then stained with fast green. After washing several times with distilled water, sections were mounted on slides using DPx. A total of 250 transverse sections (5 sections per cultivar) were observed under a light microscope (Olympus CH30RF200, Japan) and images were taken at $40 \times, 100 \times$, and $400 \times$ magnification with a Zeiss, AxiocamERc5s digital camera (Jena, Germany) to determine several leaf blade features according to the method of Ref. 16. The leaf anatomical parameters investigated include leaf width (LW), number of large vascular bundles $\left(N_{\mathrm{LVB}}\right)$, number of small vascular bundles $\left(N_{\mathrm{SVB}}\right)$, total number of vascular bundles $\left(N_{\mathrm{TVB}}\right)$, leaf thickness $\left(T_{\mathrm{L}}\right)$, vertical length of lateral vascular bundle $\left(L_{\mathrm{VLR}}\right)$, horizontal length of lateral vascular bundle $\left(L_{\mathrm{HLR}}\right)$, area of xylem vessels in lateral vascular bundle $\left(A_{\mathrm{XY}}\right)$, total area of xylem vessels $\left(A_{\mathrm{TXY}}\right)$, bulliform cell depth $\left(D_{\mathrm{BC}}\right)$, bulliform cell width $\left(W_{\mathrm{BC}}\right)$, distance between large vascular bundles $\left(D_{\mathrm{IVB}}\right)$, distance between large and small vascular bundles $\left(D_{\mathrm{LSVB}}\right)$ and distance between small vascular bundles $\left(D_{\mathrm{SVB}}\right)$ (Fig. 1$)$.

\section{Clearing technique}

Clearing technique was utilized to study the dimension and density of stomata. In brief, leaf segments of approximately $0.5 \mathrm{~cm}$ in length from the middle zones of leaf blade were cleared in $5 \% \mathrm{KOH}$ to dissolve protoplasts, followed by $3 \%$ sodium hypochlorite for complete clearing. Following dehydration with a series of ethanol, the cleared leaf segments were stained with $1 \%$ safranin $\mathrm{O}$ in $70 \%$ ethanol or chlorazol black E. They were transferred to xylene and mounted permanently on slides (modified from Ref. 17). A total of 125 leaf segments (5 per cultivar) were observed under a light microscope and images were taken using a digital camera to exam- 

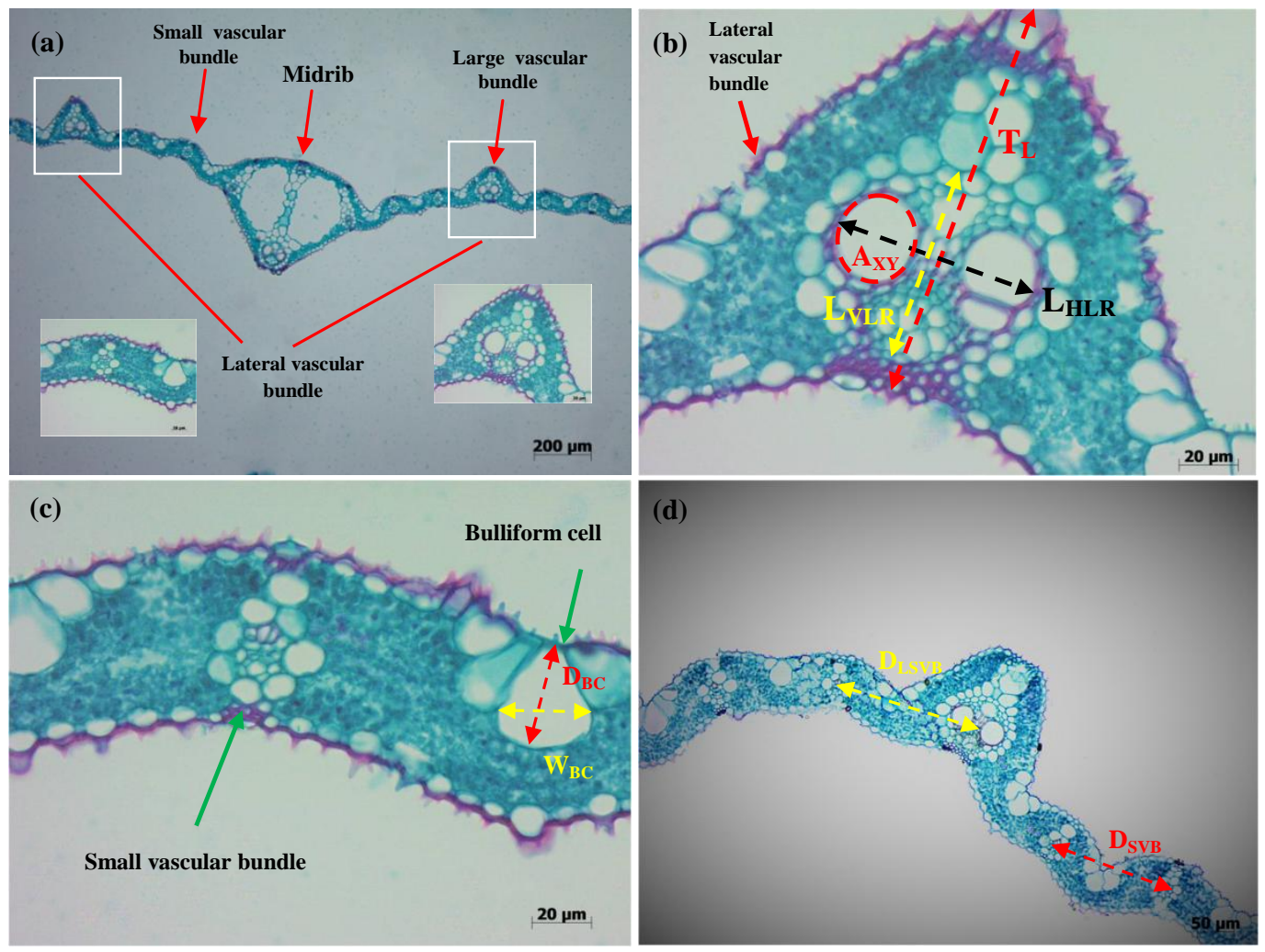

Fig. 1 Leaf cross sections of rice cv. KDML105 indicating the analysed areas: (a) overview of leaf transverse section, (b) lateral vascular bundles showing leaf thickness $\left(T_{\mathrm{L}}\right)$, vertical length of lateral vascular bundle $\left(L_{\mathrm{VLR}}\right)$, horizontal length of lateral vascular bundle $\left(L_{\mathrm{HLR}}\right)$, area of xylem vessels in lateral vascular bundle $\left(A_{\mathrm{XY}}\right)$, (c) a small vascular bundle and bulliform cells showing bulliform cell depth $\left(D_{\mathrm{BC}}\right)$ and bulliform cell width $\left(W_{\mathrm{BC}}\right)$ (d) leaf cross section showing the distance between large vascular bundles $\left(D_{\mathrm{LVB}}\right)$ and small vascular bundles $\left(D_{\mathrm{LSVB}}\right)$.

ine the leaf stomatal dimension and density, including stomatal density on adaxial epidermis $\left(D_{\text {SUE }}\right)$, stomatal density on abaxial epidermis $\left(D_{\text {SLE }}\right)$, stomatal length on adaxial epidermis $\left(L_{\mathrm{SUE}}\right)$, stomatal length on abaxial epidermis $\left(L_{\mathrm{SLE}}\right)$, stomatal width on adaxial epidermis $\left(W_{\text {SUE }}\right)$, and stomatal width on abaxial epidermis $\left(W_{\text {SLE }}\right)$. The description of all leaf anatomical traits is summarized in Table 2.

\section{Statistical analysis}

All calculations and determinations were performed in five replicates and the results were expressed as the mean \pm one standard error. The data were statistically processed with SPSS (version 16.0). The one-way ANOVA with Duncan's multiple range test was employed to determine if the means were significantly different. Significance was set at $p<$ 0.05 . The general structure of sample variability was established by cluster analysis and principal component analysis (PCA), using PC-ORD (version
5.10). These analyses were carried out to assess patterns of variation of analysed parameters, as well as to point out anatomical variables that most strongly contributed to the total variation of the sample and differences between genotypes.

\section{RESULTS}

\section{Leaf anatomical measurements/characteristics in CSSLS of KDML105}

The basic anatomical features of the leaf are consistent across all studied CSSL lines, parental lines/cultivars and standard drought-tolerant checks. However, several leaf quantitative traits varied among genotypes (Figs. 2-7). Considering the leaf width (LW), it was observed that the drought-tolerant cultivars IR62266, DH212 and CT9993 showed a significantly greater leaf width as compared with the drought-sensitive KDML105 (Fig. 2a). As expected, 16 out of 20 CSSLs had wider leaf than KDML105, with those of CSSL-3, CSSL-4, CSSL-7, CSSL-8, 
Table 2 Leaf anatomical traits investigated in this study.

\begin{tabular}{|c|c|c|}
\hline Abbreviation & Designation & Description \\
\hline LW & Leaf width & Measured at the middle of leaf blade using a ruler \\
\hline LVB & Large vascular bundle & Vascular bundles with fully developed xylem and phloem tissues \\
\hline$N_{\text {LVB }}$ & Number of LVB & Total number of LVB in a leaf cross section \\
\hline SVB & Small vascular bundle & Small sized vascular bundles \\
\hline$N_{\text {SVB }}$ & Number of SVB & Total number of SVB in a leaf cross section \\
\hline$N_{\text {TVB }}$ & Total number of vascular bundles & Sum of $N_{\mathrm{LVB}}$ and $N_{\mathrm{SVB}}$ \\
\hline LR & Lateral vascular bundle & Large vascular bundles adjacent to the midrib on both sides \\
\hline$T_{\mathrm{L}}$ & Leaf thickness & $\begin{array}{l}\text { Measured at LR from the top of the upper epidermis to the bottom } \\
\text { of the lower epidermis }\end{array}$ \\
\hline$L_{\mathrm{VLR}}$ & Vertical length of LR & The height of LR measured along the vertical axis \\
\hline$L_{\mathrm{HLR}}$ & Horizontal length of LR & The width of LR measured along the horizontal axis \\
\hline$A_{\mathrm{XY}}$ & Area of xylem vessels in LR & The area of xylem vessels in the LR (a total of 4 vessels) \\
\hline$A_{\mathrm{TXY}}$ & Total area of xylem vessels & The sum of area of xylem vessels in all LVB in the cross section \\
\hline$D_{\mathrm{BC}}$ & Bulliform cell depth & The vertical length of the largest bulliform cell \\
\hline$W_{\mathrm{BC}}$ & Bulliform cell width & The width of the largest bulliform cell measured at its widest \\
\hline$D_{\mathrm{LVB}}$ & Distance between LVB & The distance from the centre of one LVB to that of the next LVB \\
\hline$D_{\mathrm{LSVB}}$ & Distance between LVB and SVB & The distance from the centre of one LVB to that of the next SVB \\
\hline$D_{\text {SVB }}$ & Distance between SVB & The distance from the centre of one SVB to that of the next SVB \\
\hline$D_{\mathrm{SUE}}$ & Stomatal density on $\mathrm{ADE}^{*}$ & The number of stomata $\mathrm{mm}^{-2}$ of leaf surface at the upper epidermis \\
\hline$D_{\mathrm{SLE}}$ & Stomatal density on $\mathrm{ABE}^{*}$ & The number of stomata $\mathrm{mm}^{-2}$ of leaf surface at the lower epidermis \\
\hline$L_{\mathrm{SUE}}$ & Stomatal length on $\mathrm{ADE}^{*}$ & The length of stomata on the upper epidermis \\
\hline$L_{\mathrm{SLE}}$ & Stomatal length on $\mathrm{ABE}^{*}$ & The length of stomata on the lower epidermis \\
\hline$W_{\text {SUE }}$ & Stomatal width on $\mathrm{ADE}^{*}$ & The width of stomata on the upper epidermis \\
\hline$W_{\mathrm{SLE}}$ & Stomatal width on $\mathrm{ABE}$ & The width of stomata on the lower epidermis \\
\hline
\end{tabular}

" $\mathrm{ADE}=$ adaxial epidermis; $\mathrm{ABE}=$ abaxial epidermis.

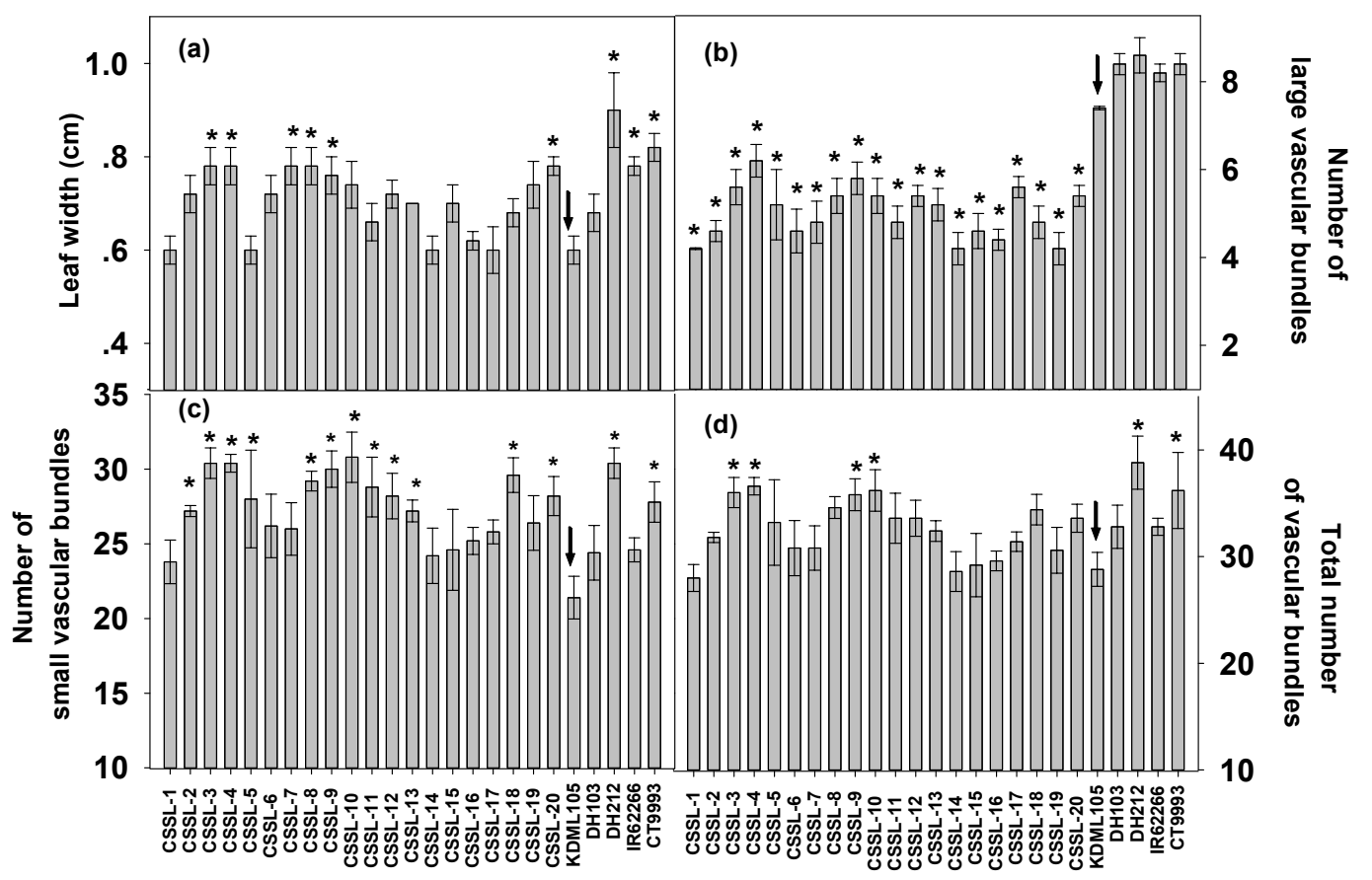

Fig. 2 (a) Leaf width (LW), (b) number of large vascular bundles $\left(N_{\mathrm{SVB}}\right)$, (c) number of small vascular bundles $\left(N_{\mathrm{LVB}}\right)$, and (d) total number of vascular bundles $\left(N_{\mathrm{TVB}}\right)$ of the 25 studied rice lines/cultivar. ${ }^{*}=$ significantly different from that of KDML105 at $p<0.05$. 


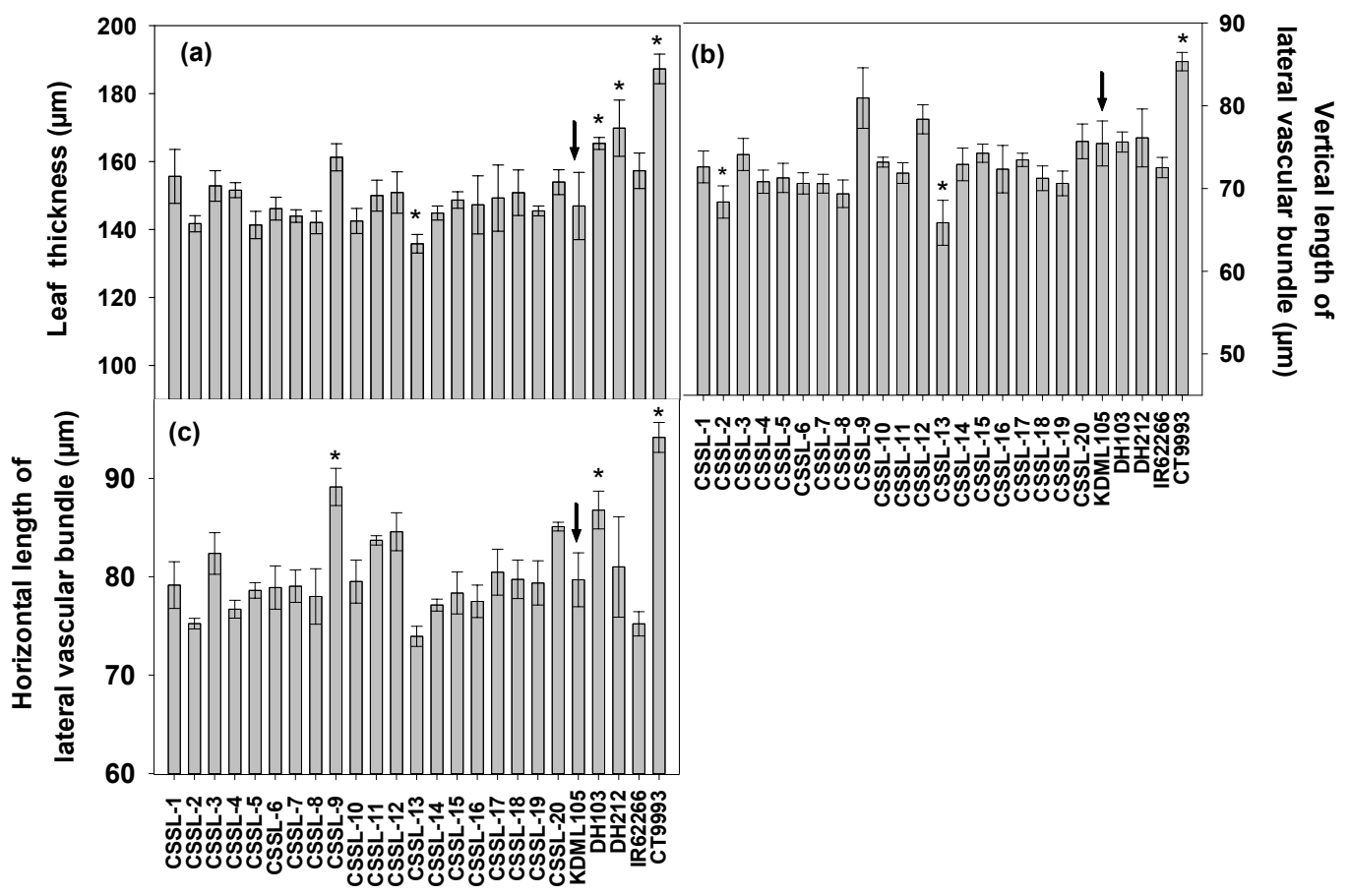

Fig. 3 (a) Leaf thickness $\left(T_{\mathrm{L}}\right)$, (b) vertical $\left(L_{\mathrm{VLR}}\right)$ and (c) horizontal $\left(L_{\mathrm{HLR}}\right)$ lengths of lateral vascular bundles of the 25 studied rice lines/cultivar. * = significantly different from that of KDML105 at $p<0.05$.

CSSL-9, and CSSL-20 significantly wider. As with LW, the studied rice cultivars showed significant differences in the numbers of large vascular bundles $\left(N_{\mathrm{LVB}}\right)$ (Fig. 2b). The drought-tolerant cultivars IR62266, CT9993, DH103 and DH212 exhibited the 2-fold greater $N_{\text {LVB }}$ than CSSLs, with the highest observed in DH212 (8.6). As compared with KDML105 (7.4), $N_{\mathrm{LVB}}$ are significantly lower in all CSSLs (4.2-5.8). Significant differences were also observed for the numbers of small vascular bundles $\left(N_{\text {SVB }}\right)$. Among the studied rice lines, KDML105 had the lowest (21.40) $N_{\mathrm{SVB}}$ (Fig. 2c). Meanwhile, $N_{\mathrm{SVB}}$ in all 20 CSSLs had higher $N_{\text {SVB }}$ than KDML105. The highest $N_{\text {SVB }}$ was recorded in CSSL-10 (30.80) followed by DH212, CSSL-3, and CSSL-4 (30.40). The total numbers of vascular bundles $\left(N_{\mathrm{TVB}}\right)$ in drought-tolerant lines and 18 CSSLs were greater than those of KDML105 (28.8), with significant differences found in CSSL-3, CSSL-4, CSSL-9, and CSSL-10 (Fig. 2d).

The leaf thickness $\left(T_{\mathrm{L}}\right)$ was defined as the mean thickness at the ridges of lateral vascular bundles (Fig. 3a). The $T_{\mathrm{L}}$ of the studied rice lines was in a range of $135.8-187.3 \mu \mathrm{m}$, with the highest value observed in CT9993 (1.27-fold greater than KDML105), followed by DH212 $(169.9 \mu \mathrm{m})$ and DH103 $(165.4 \mu \mathrm{m})$. The $T_{\mathrm{L}}$ of the 20 studied CSSLs ranged from 135.8 (CSSL-13) to $161.3 \mu \mathrm{m}$ (CSSL9), most of which were not significantly different from KDML105 $(147.0 \mu \mathrm{m})$.

Detailed anatomical characteristics of the large vascular bundles were recorded in the two large vascular bundles most adjacent to the midrib, defined as lateral vascular bundles (LR). As shown in Fig. 3b, CT9993 showed the highest vertical length of lateral vascular bundles $\left(L_{\mathrm{VLR}}\right)$ of $85.35 \mu \mathrm{m}$, followed by CSSL-9 $(80.94 \mu \mathrm{m})$, CSSL-12 $(78.37 \mu \mathrm{m})$, CSSL-20 $(75.70 \mu \mathrm{m})$ and KDML105 $(75.45 \mu \mathrm{m})$. The $L_{\mathrm{VLR}}$ of other CSSLs and other parent lines was comparable to that of KDML105 except for that of CSSL-13 $(65.87 \mu \mathrm{m})$ and CSSL-2 $(68.37 \mu \mathrm{m})$ which were significantly lower than KDML105. Similarly, the largest horizontal length $(94.17 \mu \mathrm{m})$ of lateral vascular bundles $\left(L_{\mathrm{HLR}}\right)$, shown in Fig. 3c, was observed in CT9993 $(94.17 \mu \mathrm{m})$, which was significantly different from other lines/cultivars. CSSL-9 showed the second largest $L_{\mathrm{HLR}}$ of $89.14 \mu \mathrm{m}$, which was significantly larger than KDML105 $(79.70 \mu \mathrm{m})$.

Again, CT9993 exhibited the largest area of xylem vessels $\left(A_{X Y}\right)$, defined as the area of the 4 largest xylem vessels in the two LR, of $424.1 \mu \mathrm{m}^{2}$ when compared with the remaining genotypes (Fig. 4a), followed by CSSL-9 $\left(380.4 \mu \mathrm{m}^{2}\right)$ and KDML105 $\left(348.4 \mu \mathrm{m}^{2}\right)$. Among CSSLs, the $A_{\mathrm{XY}}$ 


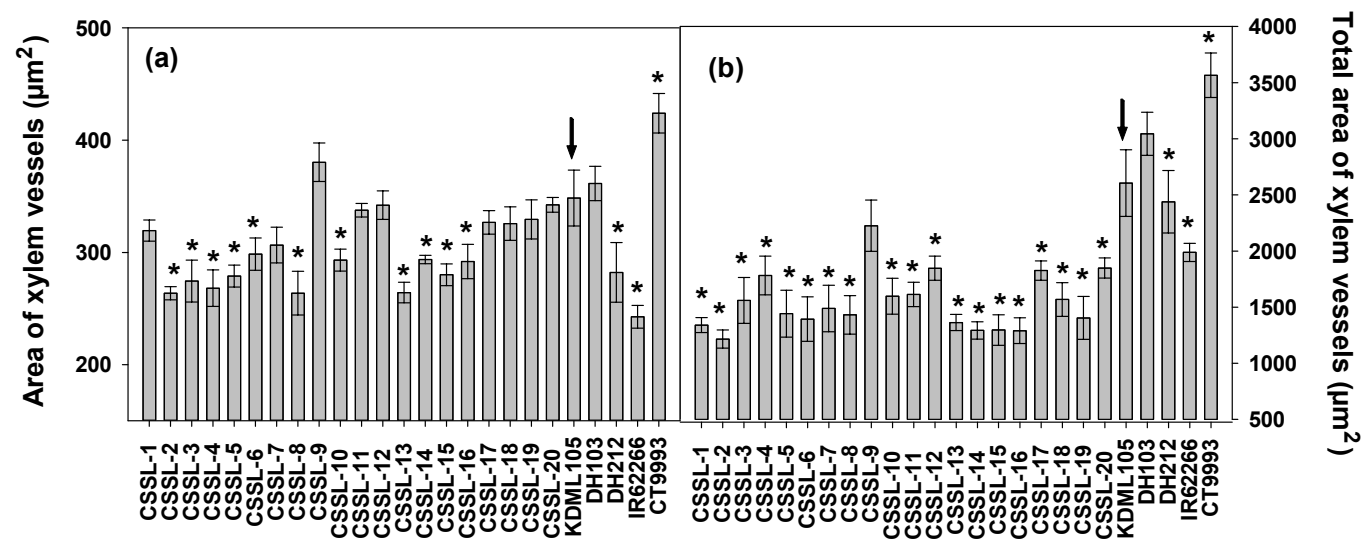

Fig. 4 Area of xylem vessels in the lateral vascular bundle $\left(A_{\mathrm{XY}}\right)$ (a) and total area of xylem vessels $\left(A_{\mathrm{TXY}}\right)$ (b) of the studied 25 rice lines/cultivar. * = significantly different from that of KDML105 at $p<0.05$.

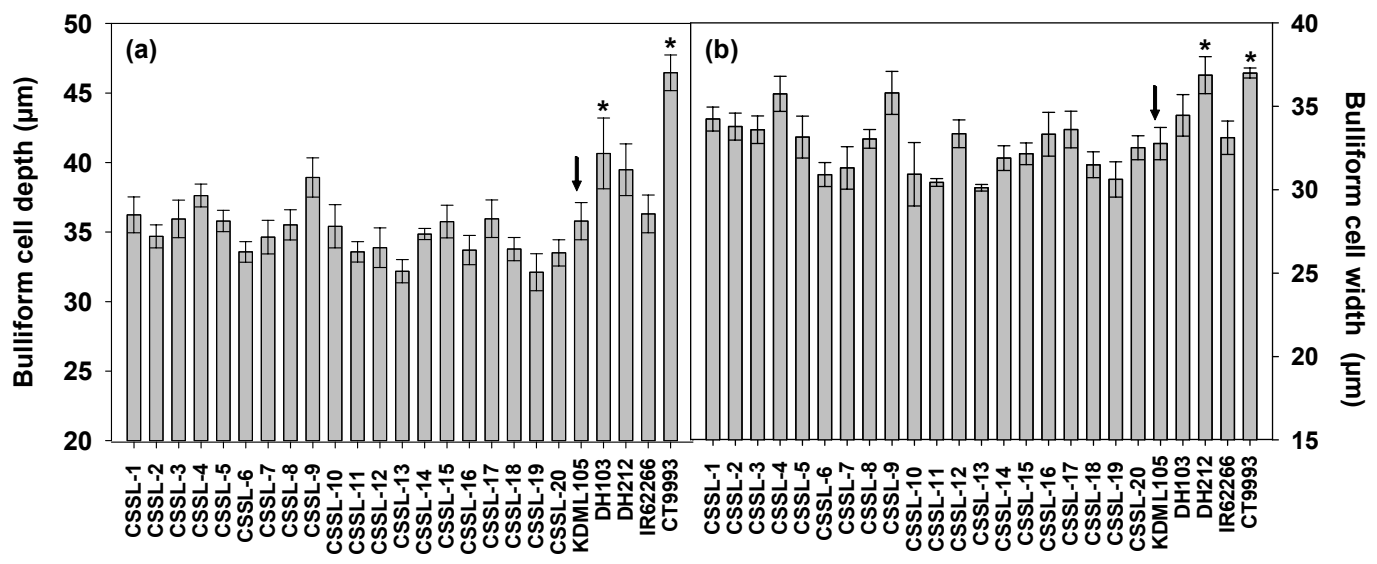

Fig. 5 Bulliform cell (a) depth $\left(W_{\mathrm{BC}}\right)$ and (b) width $\left(D_{\mathrm{BC}}\right)$ of the 25 studied rice lines/cultivar. * = significantly different from that of KDML105 at $p<0.05$.

of CSSL-9 was significantly greater than those of other CSSLs. The $A_{\mathrm{XY}}$ in CT9993 was 1.75 -fold greater than that of IR62266 $\left(242.7 \mu \mathrm{m}^{2}\right)$ which had the lowest $A_{\mathrm{XY}}$ of all genotypes. The total area of xylem vessels $\left(A_{\mathrm{TXY}}\right)$, defined as the total area of xylem vessels in all LVB in the cross section, appeared to be higher in drought-tolerant cultivars than in CSSLs (Fig. 4b), with the highest value observed in CT9993 $\left(3566 \mu \mathrm{m}^{2}\right)$. DH103 and DH212 showed the $A_{\mathrm{TXY}}$ of approximately 3044 and $2439 \mu \mathrm{m}^{2}$, respectively. On the other hand, the $A_{\text {TXY }}$ of IR62266 $\left(1988 \mu \mathrm{m}^{2}\right)$ was significantly lower than that of other drought-tolerant cultivars. The $A_{\mathrm{TXY}}$ in KDML105 $\left(2605 \mu \mathrm{m}^{2}\right)$ was not significantly different from DH103 $\left(3044 \mu \mathrm{m}^{2}\right)$ and DH212 $\left(2439 \mu \mathrm{m}^{2}\right)$. The $A_{\mathrm{TXY}}$ in CSSLs was in a range of $1216 \mu \mathrm{m}^{2}$ (CSSL-2) to $2226 \mu \mathrm{m}^{2}$ (CSSL-9).

For bulliform cell dimensions (Fig. 5), CT9993 exhibited the highest bulliform cell depth $\left(D_{\mathrm{BC}}\right)$ and width $\left(W_{\mathrm{BC}}\right)$ of 46.46 and $37.00 \mu \mathrm{m}$, respectively. Both $D_{\mathrm{BC}}$ and $W_{\mathrm{BC}}$ of all 20 CSSLs were not significantly different from KDML105 which had $D_{\mathrm{BC}}$ and $W_{\mathrm{BC}}$ of 35.79 and $32.77 \mu \mathrm{m}$, respectively. When compared to other CSSLs, higher $D_{\mathrm{BC}}$ and $W_{\mathrm{BC}}$ were observed in CSSL-9, showing $D_{\mathrm{BC}}$ and $W_{\mathrm{BC}}$ of $38.93 \mu \mathrm{m}$ and $35.81 \mu \mathrm{m}$, respectively.

\section{Stomatal characteristics in CSSLS of KDML105}

The stomatal density of both adaxial $\left(D_{\mathrm{SUE}}\right)$ and abaxial $\left(D_{\mathrm{SLE}}\right)$ leaf surface in KDML105 was lower than the four drought-tolerant cultivars (Fig. 6a,b). The stomatal density in CSSL- 4 and CSSL- 9 was significantly higher than that observed in KDML105 and other CSSLs. The $D_{\text {SUE }}$ values in CSSL4 and CSSL-9 were approximately 316.4 and $341.5 \mathrm{~mm}^{-2}$, respectively, which were consid- 


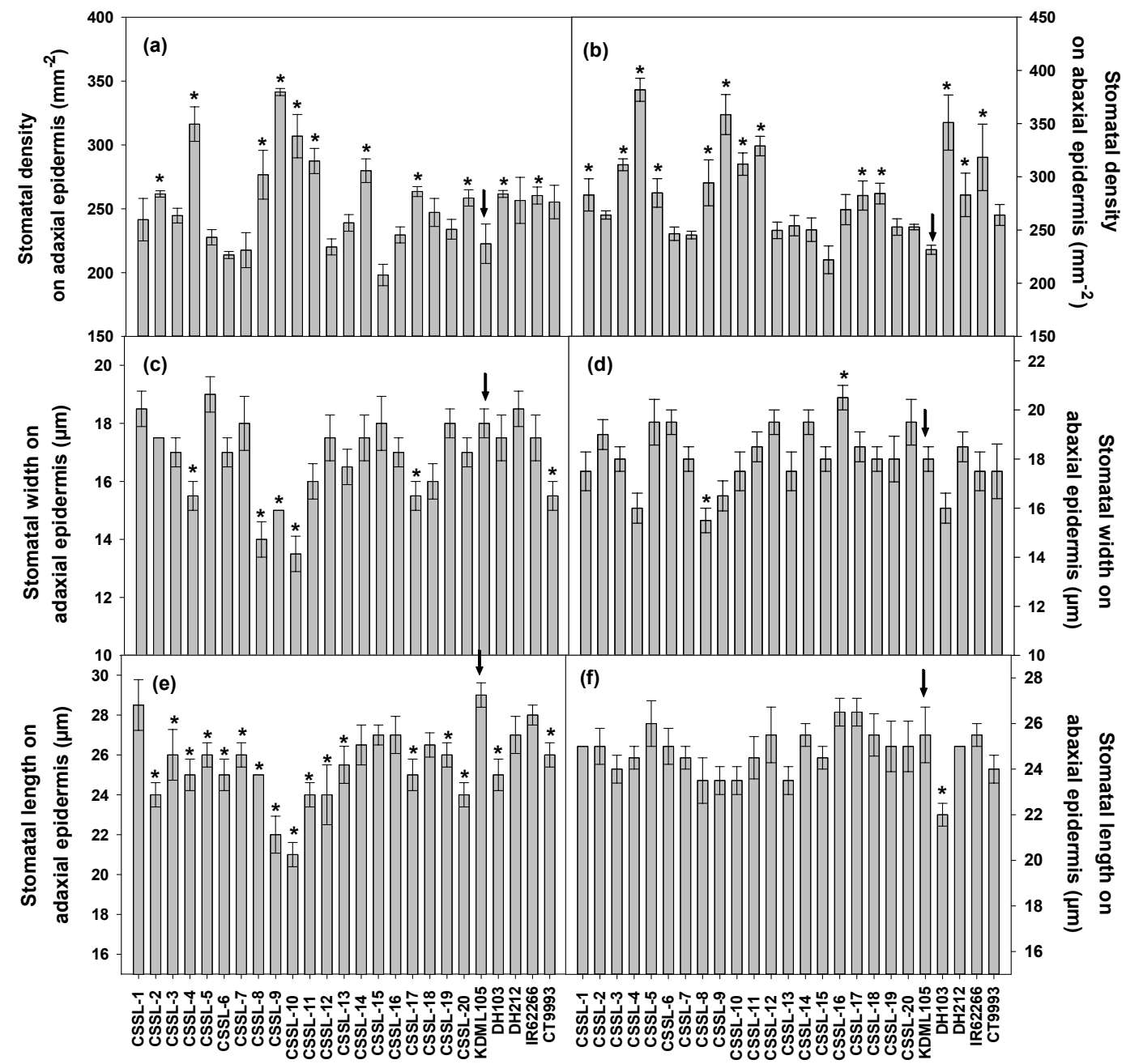

Fig. 6 Stomatal density on (a) adaxial $\left(D_{\text {SUE }}\right)$ and (b) abaxial $\left(D_{\text {SLE }}\right)$ epidermis, stomatal width on (c) adaxial $\left(W_{\text {SUE }}\right)$ and (d) abaxial $\left(W_{\mathrm{SLE}}\right)$, and stomatal length on (e) adaxial $\left(L_{\mathrm{SUE}}\right)$ and (f) abaxial $\left(L_{\mathrm{SLE}}\right)$ epidermis of the 25 studied rice lines/cultivar. * = significantly different from that of KDML105 at $p<0.05$.

erably higher than that observed in KDML105 $\left(222.6 \mathrm{~mm}^{-2}\right.$ ). All CSSLs (except CSSL-15) had higher $D_{\mathrm{SLE}}$ than KDML105. Numerous $D_{\mathrm{SLE}}$ was found in CSSL-4 $\left(381.8 \mathrm{~mm}^{-2}\right)$ and CSSL-9 $\left(358.5 \mathrm{~mm}^{-2}\right)$ which were much greater than that in KDML105 $\left(231.5 \mathrm{~mm}^{-2}\right)$. The $D_{\text {SUE }}$ of CSSL4 and CSSL- 9 were significantly higher than all 4 drought-tolerant checks, however their $D_{\text {SLE }}$ values were higher than for DH212, IR62266, and CT9993.

The stomatal width measured on the adaxial surface $\left(W_{\text {SUE }}\right)$ of both CSSLs and KDML105 was slightly different, which ranged between 13.50 and $19.00 \mu \mathrm{m}$ (Fig. 6c). KDML105 exhibited significantly greater $W_{\text {SUE }}$ as compared to CT9993, CSSL4, CSSL-8, CSSL-9, CSSL-10, and CSSL-17. On the other hand, CSSL- 8 , CSSL- 9 , and CSSL-10 were observed to show smaller $W_{\text {SUE }}$ than the remaining CSSLs. The stomatal width of abaxial surface $\left(W_{\text {SLE }}\right)$ in CSSLs ranged between 15.50 (CSSL-8) to $20.50 \mu \mathrm{m}$ (CSSL-16) (Fig. 6d). CSSL-16 also exhibited significantly greater $W_{\mathrm{SUE}}$ than parental lines.

The stomatal length on the adaxial surface $\left(L_{\text {SUE }}\right)$ in KDML105, IR62266, DH212 and CSSL1, CSSL-14, CSSL-15, CSSL-16, and CSSL-18 were not significantly different ranging from 26.50$29.00 \mu \mathrm{m}$, with KDML105 displaying the highest stomatal length (Fig. 6e). All CSSLs (except CSSL1) had significantly shorter $L_{\text {SUE }}$ than KDML105. The stomatal length on the abaxial surface $\left(L_{\mathrm{SLE}}\right)$ observed in DH103 was smaller than those in all CSSLs and KDML105 (Fig. 6f). 


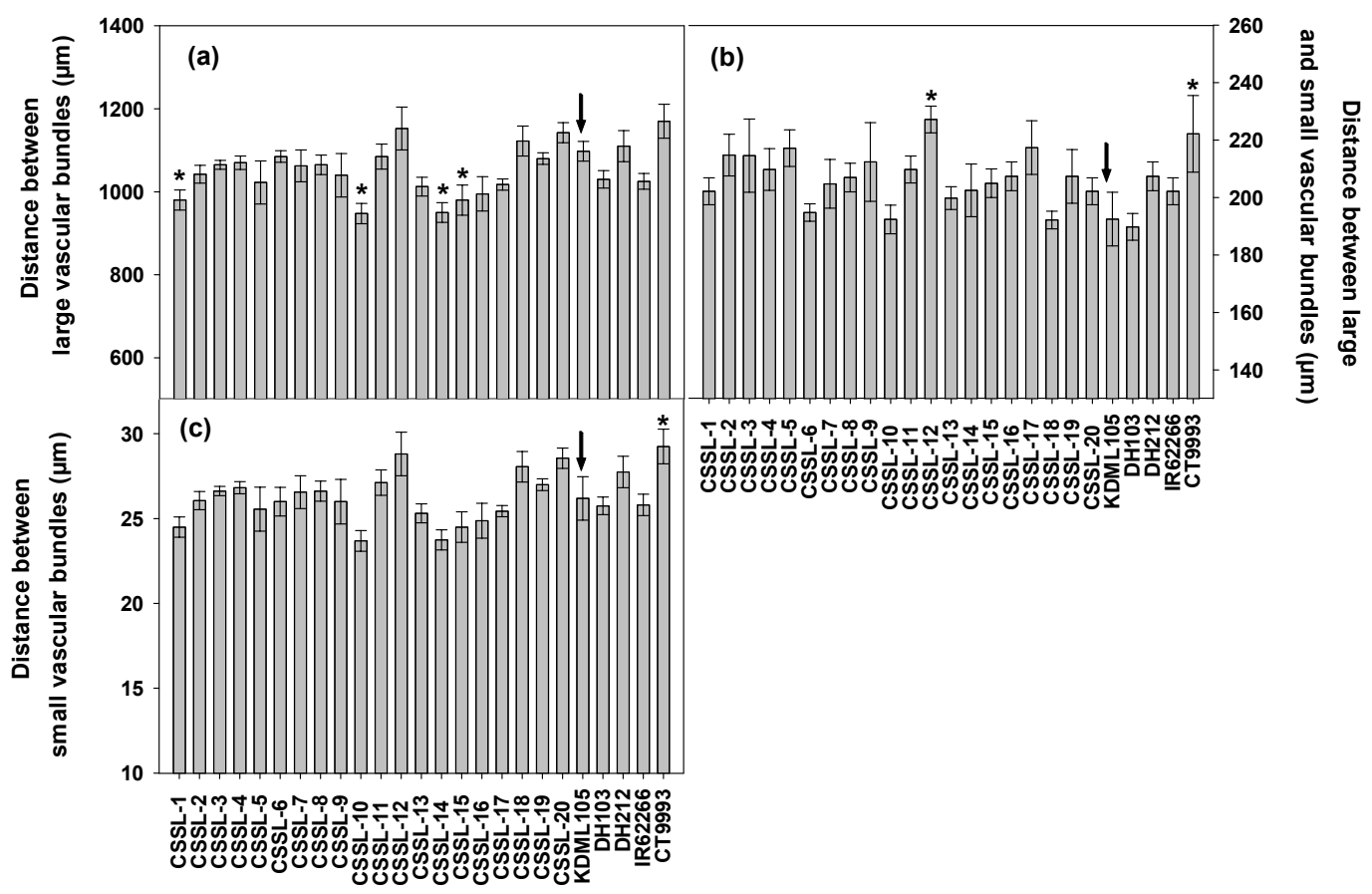

Fig. 7 Distance (a) between adjacent large vascular bundles $\left(D_{\mathrm{LVB}}\right)$, (b) between adjacent small vascular bundles $\left(D_{\mathrm{SVB}}\right)$, and (c) between small and large vascular bundles $\left(D_{\mathrm{LSVB}}\right)$ of the 25 studied rice lines/cultivar. * = significantly different from that of KDML105 at $p<0.05$.

\section{Patterns of vascular tissues in CSSLs of KDML105}

Leaf cross section, in general, displays the distance between adjacent vascular bundles, in which three major distances could be measured (Fig. 7): (1) the distance between adjacent large vascular bundles, (2) the distance between adjacent large and small vascular bundles, and (3) the distance between adjacent small vascular bundles. The distance between adjacent large vascular bundles (Fig. 7a) ranged from approximately $947.0-1170.0 \mu \mathrm{m}$. The distance between adjacent large vascular bundles in CSSL-1, CSSL-10, CSSL-14, and CSSL-15 was significantly shorter than that in other CSSLs, KDML105 $(1097.5 \mu \mathrm{m})$ and parental lines (1025.0$1170.0 \mu \mathrm{m})$. The distance between large and small vascular bundles (Fig. 7b) was not significantly different among CSSLs and parental lines. However, CSSL-12 $(227.2 \mu \mathrm{m})$ and CT9993 $(222.2 \mu \mathrm{m})$ exhibited the longest distance between large and small vascular bundles, as compared to other CSSLs. The distance between small vascular bundles (Fig. 7c) in all CSSLs was found in a range of $23.69 \mu \mathrm{m}$ (CSSL10) to $28.81 \mu \mathrm{m}$ (CSSL-12), which did not differ significantly from that of KDML105 $(26.19 \mu \mathrm{m})$. Among the parental lines, СT9993 exhibited the greatest distance of $29.25 \mu \mathrm{m}$. Among the CSSLs, CSSL-10 exhibited the shortest of all three types of distance, whereas CSSL-12 showed the longest.

For patterns of the vascular bundle arrangement in leaf blade, it was observed that the vascular bundle arrangement in CSSLs and parental lines were asymmetric regarding the number of small and large vascular bundles. The ratio of large vascular bundles to small vascular bundles in the leaf of KDML105 was 1:2.8 while that of CSSLs was approximately 1:5. The average number of large vascular bundles per leaf was 8-9 in droughttolerant cultivars, 7 in KDML105 and 4-5 in CSSLs. In contrast, CSSLs and drought-tolerant cultivars showed the average number of small vascular bundles per leaf of 24-30 which are greater than that of KDML105 (21). The number of small vascular bundles located between neighbouring large vascular bundles varied considerably from 2-7.

\section{Correlations between anatomical characteristics in CSSLs of KDML105}

The correlations among leaf anatomical features are shown in Table 3. LW was positively correlated with $N_{\mathrm{LVB}}, N_{\mathrm{SVB}}$, and $N_{\mathrm{TVB}}$. In contrast, LW showed negative correlations with $L_{\mathrm{SLE}}$. The $N_{\mathrm{LVB}}$ was posi- 
Table 3 The correlations among different leaf anatomical parameters.

\begin{tabular}{|c|c|c|c|c|c|c|c|c|c|c|c|c|c|c|c|c|c|c|c|c|}
\hline \multirow[t]{2}{*}{ Trait } & \multicolumn{20}{|c|}{$r$ value } \\
\hline & LW & $N_{\mathrm{LVB}}$ & $N_{\text {SVB }}$ & $N_{\mathrm{TVB}}$ & $T_{\mathrm{L}}$ & $L_{\mathrm{VLR}}$ & $L_{\mathrm{HLR}}$ & $A_{X Y}$ & $A_{\mathrm{TXY}}$ & $D_{\mathrm{LVB}}$ & $D_{\text {LSVB }}$ & $D_{\text {SVB }}$ & $D_{\mathrm{BC}}$ & $W_{\mathrm{BC}}$ & $D_{\text {SUE }}$ & $D_{\text {SLE }}$ & ${ }_{\text {SUE }}$ & ${ }^{{ }^{L} \mathrm{SLE}}$ & $w_{\text {SUE }}$ & $w_{\mathrm{SLE}}$ \\
\hline LW & 1 & & & & & & & & & & & & & & & & & & & \\
\hline$N_{\mathrm{LVB}}$ & $0.47^{\text {*k }}$ & 1 & & & & & & & & & & & & & & & & & & \\
\hline$N_{\mathrm{SVB}}$ & $0.66^{\text {*k }}$ & $0.23^{*}$ & 1 & & & & & & & & & & & & & & & & & \\
\hline$N_{\text {TVB }}$ & $0.73^{* *}$ & $0.53^{* *}$ & $0.95^{* *}$ & 1 & & & & & & & & & & & & & & & & \\
\hline$T_{\mathrm{L}}$ & $0.27^{* k *}$ & $0.48^{* * *}$ & 0.00 & 0.16 & 1 & & & & & & & & & & & & & & & \\
\hline${ }^{L_{\mathrm{VLR}}}$ & $0.28^{k *}$ & $0.37^{* * *}$ & 0.04 & 0.16 & $0.71^{* *}$ & 1 & & & & & & & & & & & & & & \\
\hline$L_{\mathrm{HLR}}$ & $0.25^{* *}$ & $0.37^{* * *}$ & $0.18^{*}$ & $0.28^{* *}$ & $0.62^{* *}$ & $0.69^{* *}$ & 1 & & & & & & & & & & & & & \\
\hline$A_{X Y}$ & 0.11 & $0.27^{* * *}$ & 0.08 & 0.16 & $0.51^{* *}$ & $0.61^{\text {** }}$ & $0.81^{* *}$ & 1 & & & & & & & & & & & & \\
\hline$A_{\mathrm{TXY}}$ & $0.38^{k * k}$ & $0.86^{* * *}$ & $0.19^{*}$ & $0.45^{* *}$ & $0.61^{* *}$ & $0.58^{* *}$ & $0.68^{* * *}$ & $0.70^{* *}$ & 1 & & & & & & & & & & & \\
\hline$D_{\mathrm{LVB}}$ & $0.30^{k * k}$ & $0.24^{* * *}$ & 0.17 & $0.22^{*}$ & $0.22^{*}$ & $0.30^{* *}$ & $0.29^{* k}$ & $0.29^{* *}$ & $0.32^{* * k}$ & 1 & & & & & & & & & & \\
\hline$D_{\mathrm{LSVB}}$ & 0.13 & 0.01 & $0.19^{*}$ & 0.17 & 0.10 & 0.17 & 0.09 & 0.11 & 0.06 & $0.26^{\text {** }}$ & 1 & & & & & & & & & \\
\hline$D_{\mathrm{SVB}}$ & $0.33^{k * k}$ & $0.21^{*}$ & $0.19^{*}$ & $0.23^{* *}$ & $0.23^{* *}$ & $0.30^{* *}$ & $0.30^{* *}$ & $0.28^{* *}$ & $0.29^{* k *}$ & $0.93^{\text {** }}$ & $0.31^{* * k}$ & 1 & & & & & & & & \\
\hline$D_{\mathrm{BC}}$ & $0.35^{* *}$ & $0.58^{* * *}$ & 0.10 & $0.29^{* * *}$ & $0.53^{* *}$ & $0.54^{* * *}$ & $0.53^{* *}$ & $0.45^{* *}$ & $0.69^{k * k}$ & $0.19^{*}$ & 0.08 & 0.18 & 1 & & & & & & & \\
\hline$w_{\mathrm{BC}}$ & $0.36^{k *}$ & $0.44^{* * *}$ & $0.23^{*}$ & $0.36^{* * *}$ & $0.41^{k *}$ & $0.39^{* *}$ & $0.28^{* k}$ & $0.24^{* * *}$ & $0.49^{* * k}$ & $0.23^{* *}$ & $0.26^{* k *}$ & $0.26^{k * k}$ & $0.62^{* * *}$ & 1 & & & & & & \\
\hline$D_{\text {SUE }}$ & 0.09 & 0.10 & $0.20^{*}$ & $0.21^{*}$ & 0.10 & 0.08 & 0.11 & 0.10 & 0.11 & -0.11 & 0.09 & -0.09 & $0.20^{*}$ & 0.17 & 1 & & & & & \\
\hline$D_{\mathrm{SLE}}$ & 0.14 & $0.22^{*}$ & $0.27^{* *}$ & $0.31^{* *}$ & 0.04 & 0.01 & 0.09 & 0.05 & $0.18^{*}$ & -0.00 & 0.07 & 0.03 & $0.26^{* * *}$ & $0.27^{\text {*** }}$ & $0.62^{\text {** }}$ & 1 & & & & \\
\hline$L_{\text {SUE }}$ & -0.13 & 0.07 & $-0.28^{\text {** }}$ & $-0.22^{*}$ & 0.05 & -0.04 & -0.12 & -0.14 & -0.03 & -0.01 & -0.07 & -0.06 & -0.02 & 0.04 & $-0.37^{k * k}$ & $-0.26^{* * *}$ & 1 & & & \\
\hline${ }^{L_{\mathrm{SLE}}}$ & $-0.19^{*}$ & 0.03 & $-0.23^{\text {** }}$ & $-0.19^{*}$ & -0.03 & -0.13 & -0.13 & -0.11 & -0.05 & -0.01 & -0.09 & -0.02 & -0.10 & -0.05 & $-0.52^{\text {k* }}$ & $-0.32^{\text {*** }}$ & $0.41^{* *}$ & 1 & & \\
\hline$w_{\text {SUE }}$ & -0.13 & -0.14 & -0.07 & -0.11 & -0.10 & -0.04 & -0.16 & -0.08 & -0.17 & 0.02 & 0.16 & -0.03 & $-0.20^{*}$ & -0.09 & -0.04 & -0.14 & $0.25^{* *}$ & 0.16 & 1 & \\
\hline$w_{\text {SLE }}$ & -0.067 & $-0.18^{*}$ & -0.05 & -0.11 & -0.09 & 0.02 & -0.10 & 0.02 & -0.12 & 0.12 & $0.23^{*}$ & 0.11 & -0.06 & 0.04 & $-0.26^{\text {*k }}$ & $-0.21^{*}$ & 0.01 & $0.20^{*}$ & $0.22^{*}$ & 1 \\
\hline
\end{tabular}

tively correlated with the $A_{\mathrm{TXY}} \cdot T_{\mathrm{L}}$ exhibited positive correlations with the $L_{\mathrm{VLR}}, L_{\mathrm{HLR}}, A_{\mathrm{TXY}}, D_{\mathrm{BC}}$, and $W_{\mathrm{BC}}$. The $L_{\mathrm{VLR}}$ displayed positive correlations with $A_{\mathrm{xy}}, D_{\mathrm{IVB}}, D_{\mathrm{SVB}}, W_{\mathrm{BC}}$, and $D_{\mathrm{BC}}$. The $L_{\mathrm{HLR}}$ exhibited positive correlations with $A_{\mathrm{xy}}, D_{\mathrm{IVB}}, D_{\mathrm{SVB}}, W_{\mathrm{BC}}$, and $D_{\mathrm{BC}}$. The $A_{\mathrm{xy}}$ showed positive correlations with $D_{\mathrm{LVB}}$, $D_{\mathrm{SVB}}, D_{\mathrm{BC}}$, and $W_{\mathrm{BC}}$.

\section{Principal component analysis}

Eleven anatomical characteristics were selected for the principal component analysis (PCA). These parameters included LW, $N_{\mathrm{LVB}}, N_{\mathrm{SVB}}, N_{\mathrm{TVB}}, T_{\mathrm{L}}, L_{\mathrm{VLR}}$, $L_{\mathrm{HLR}}, A_{\mathrm{XY}}, A_{\mathrm{TXY}}, D_{\mathrm{BC}}$, and $W_{\mathrm{BC}}$. The PCA extracted two factors accounted for $78 \%$ of the total variance of the studied cultivars (57 and $21 \%$ for 1 st and 2nd factor, respectively). The 1st factor was related to $N_{\mathrm{LVB}}, T_{\mathrm{L}}, L_{\mathrm{VLR}}, L_{\mathrm{HLR}}, A_{\mathrm{XY}}, A_{\mathrm{TXY}}, D_{\mathrm{BC}}$, and $W_{\mathrm{BC}}$. The 2nd factor was mainly related to $\mathrm{LW}, N_{\mathrm{SVB}}, A_{\mathrm{XY}}$, and $A_{\mathrm{TXY}}$. According to these results, the studied cultivars were categorized into 7 groups: the 1 st group included CT9993, the 2nd group KDML105, the 3rd group CSSL-9, the 4th group DH103, the 5th group DH212, and the 6th group CSSL1, CSSL67, CSSL11-12, CSSL14-17, and CSSL19-20, the 7th group IR62266, CSSL-2-5 CSSL-8, CSSL-10, CSSL13, and CSSL-18 (Fig. 8).

\section{DISCUSSION}

In general, plants evolved to resist dry conditions exhibit a greater stomatal density, smaller stomatal dimensions, smaller epidermal cells, thicker cuticle, and greater number of layers of smaller mesophyll cell ${ }^{18}$. In this study, differences in the leaf anatomical characteristics were characterized in 20 CSSLs, introgressed with DT-QTLs on chromosomes $1,3,4,8$, and 9. These CSSLs are a subset of 139 CSSLs reported to have greater yields under drought stress as compared to their recurrent parent KDML105 ${ }^{12}$. For comparison, the standard drought-tolerant lines CT9993 and IR62266, QTL donor parents DH103 and DH212, and the recurrent parent KDML105 were included in the study. Among 20 leaf anatomical features studied, seven (leaf width, number and size of vascular bundles, leaf thickness, area of xylem vessels and stomata density and size) displayed large variations among the studied genotypes.

In our study, the DT-QTL donor line DH212 displayed the highest LW, $N_{\mathrm{LVB}}, N_{\mathrm{SVB}}$ as well as $N_{\mathrm{TVB}}$, as compared to other studied lines. As expected, when compared to the recurrent parent line KDML105 higher values in LW, $N_{\mathrm{SVB}}$ and $N_{\mathrm{TVB}}$ were observed for CSSLs 9-12 carrying DT-QTL located on chromosome 4 of DH212. An earlier study demonstrated that the IR64-derived lines with broader leaves performed better than those with narrow and short leaves under drought ${ }^{19}$. It was also reported that the wide leaf rice mutant which had 1.5-2 folds wider leaf than that of the wild-type also had higher chlorophyll content and better efficiency of light utilization ${ }^{20}$. LW might be controlled by certain genes on chromosome 4, as suggested by an earlier study in rice which demonstrated that the region RM255-RM349 on chromosome 4 controlled LW, 


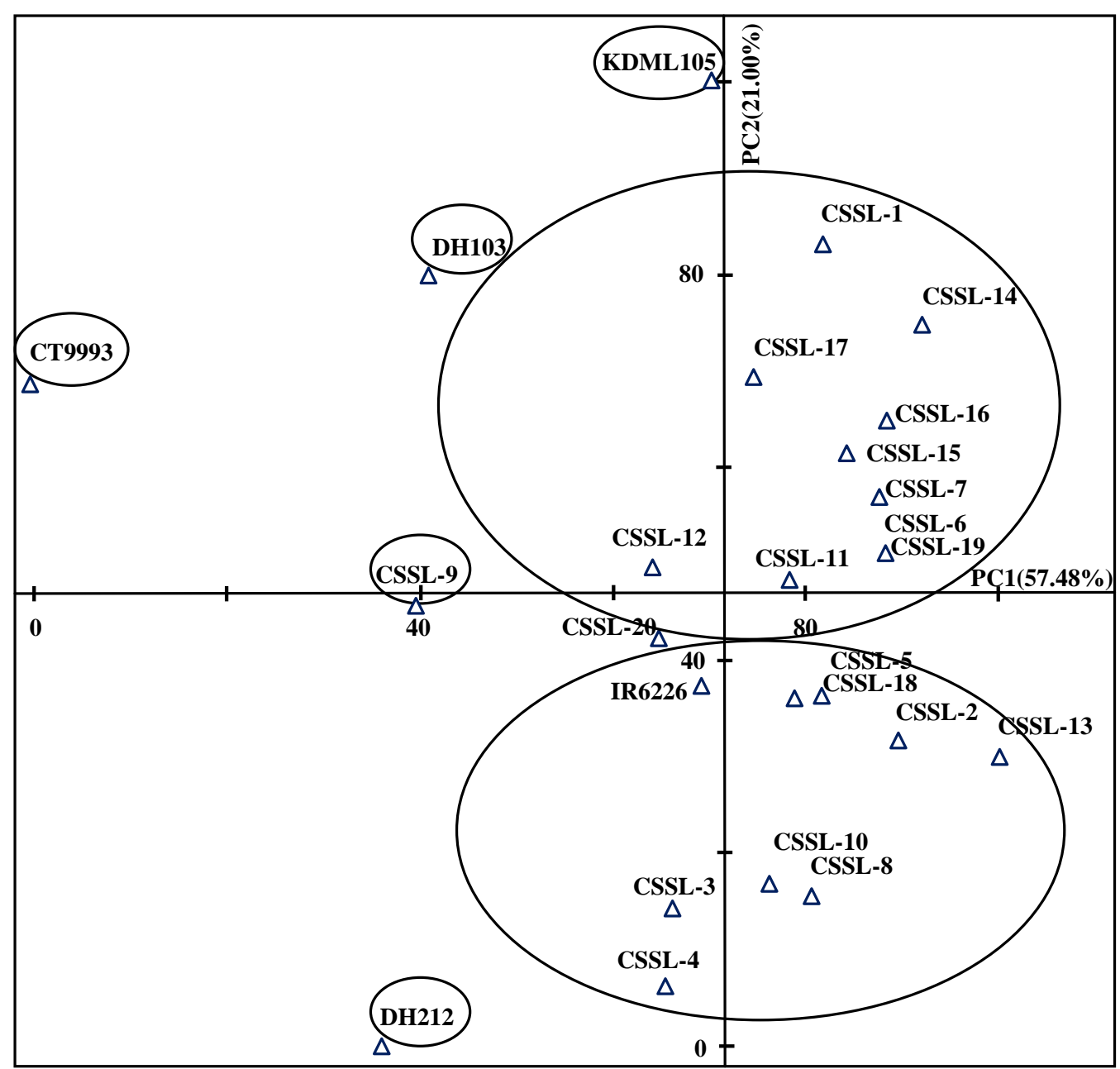

Fig. 8 Principal component analysis (PCA) carried out using 11 anatomical characteristics (leaf width LW, number of large vascular bundles $N_{\mathrm{LVB}}$, number of small vascular bundles $N_{\mathrm{SVB}}$, total number of vascular bundles $N_{\mathrm{TVB}}$, length of lateral ridge $L_{\mathrm{LR}}$, vertical length of lateral vascular bundle $L_{\mathrm{VLR}}$, horizontal length of lateral vascular bundle $L_{\mathrm{HLR}}$, area of xylem vessels in lateral vascular bundle $A_{\mathrm{XY}}$, total area of xylem vessels $A_{\mathrm{TXY}}$, bulliform cell depth $D_{\mathrm{BC}}$, and bulliform cell width $W_{\mathrm{BC}}$ ) for the 25 studied lines/cultivar.

leaf length and leaf area ${ }^{21}$.

As with the DT-QTL donor DH212, high $N_{\mathrm{TVB}}$ values were observed in CSSL-3, CSSL-4, CSSL9, CSSL-10, and the standard drought-tolerant CT9993, which was about 1.25 -fold greater than those of KDML105. $\mathrm{C}_{4}$ plants, which are more resistant to drought than $\mathrm{C}_{3}$ plants, usually maintain a high vein density and low interveinal distance due to the requirement for close proximity of mesophyll and vein-associated bundle sheath cells to facilitate a rapid cycling of metabolites, resulting in short diffusion pathways for their metabolites ${ }^{22}$. It has been proposed that xylem density may serve as a useful tool in estimating the xylem characteristics and determining drought tolerance in many species, in which a larger number of vascular bundles per $\mathrm{mm}^{2}$ of cross-section area of the main vein and a larger number of smaller vessels could be included as keys characteristic in the selection of drought tolerant genotypes ${ }^{23}$. Additionally, higher leaf vein density has been documented to enable higher rates of photosynthesis due to the enhanced water transport that allows higher leaf conductance to $\mathrm{CO}_{2}$ and water ${ }^{24}$. With respect to interveinal distances, our results with this group of genotypes showed no clear differences between the parental lines and improved CSSL lines. Although CSSL-3, CSSL-4, CSSL- 9 and CSSl-10 had significantly higher $N_{\text {TVB }}$ 
than KDML105 (Fig. 2d), they also had greater LW (Fig. 2a), therefore they had interveinal distances similar to those of KDML105 (Fig. 7). Interestingly, a recent work identified 5 EMS-mutagenized rice lines having significantly higher vein density than the parent IR6 $6{ }^{25}$. Higher vein density and short interveinal distance traits in these mutant lines were shown to be related to significantly higher photosynthesis rates.

Leaf thickness $\left(T_{\mathrm{L}}\right)$ has been considered as a crucial index in high-yield cultivars since it is one of the pivotal organs that correspond to photosynthetic efficiency in plants and is also an important trait contributed to ideotypes in rice ${ }^{26}$. Furthermore, in an earlier report, TL was found to have positive correlations with leaf length and LW indicating that thicker leaf was beneficial to increase the single leaf area thereby enhancing photosynthetic activity ${ }^{27}$. Our results demonstrated that the drought-tolerant parent lines DH103 and DH212, and the standard check line CT9333 exhibited greater leaf thickness than KDML105 (Fig. 3a). Among the studied CSSLs, CSSL-9 displayed slightly greater leaf thickness than KDML105. It was also reported that plants with thicker leaf blades may increase leaf water content under dry conditions, and reckoned that an increase in leaf thickness, vessel and vascular diameters was associated with more obvious xerophile-liked $\operatorname{traits}^{28}$. For instance, the xeric population of $\mathrm{An}$ dropogon gerardii has been reported to have thicker leaves and fewer bulliform cells when compared to the mesic population ${ }^{4}$.

The xylem in the vascular bundle is the most important architectural component in plant tissues, and the vascular bundle size and the density of bundle sheath cells are closely correlated with photosynthesis and transpiration ${ }^{29}$. Our results demonstrated that the drought-resistant line CT9993 had larger vascular bundles ( $L_{\mathrm{VLR}}$ and $L_{\mathrm{HLR}}$; Fig. 3b,c) and xylem vessel area $\left(A_{X Y} ;\right.$ Fig. $\left.4 a\right)$ than the drought-sensitive parent KDML105. Furthermore, the highest $A_{\text {TXY }}$ was observed for CT9993. Among the studied CSSLs, CSSL-9 was observed to exhibit highest $L_{\mathrm{VLR}}, L_{\mathrm{HLR}}$, and $A_{\mathrm{TXY}}$. However, all of CSSLs (including CSSL-9) displayed lower $A_{\text {TXY }}$ than KDML105 (Fig. 4b), which was due to higher number of large vascular bundles $\left(N_{\mathrm{LVB}}\right)$ in KDML105, as depicted in Fig. 2b. Xylem diameter and density have been reported to be related to increasing tolerance on short-term water deficit ${ }^{30}$ due to the fact that the size and the number of xylem vessel influence their conductivity for water transport ${ }^{31}$. Furthermore, xylem diameter was pre- viously reported to be related to the maintenance of xylem water conductivity, and the maintenance of high leaf water potential was associated with large xylem size and hence higher internal water conductance $^{8}$.

Stomata are crucial in governing water use efficiency of crops or crop yield per unit of water input determined by photosynthesis and transpiration. Stomatal density and size are considered as dominant factors for determining leaf conductance $^{32}$. In this study, it was found that the droughtsensitive KDML105 appeared to have larger stomatal size when compared to the drought-tolerant lines DH103, DH212, IR62266, CT9993, and some CSSLs (Fig. 6d). In contrast, KDML105 had lower stomatal density than drought-tolerant lines and a majority of CSSLs (Fig. 6a,b). Among the studied CSSLs, significantly higher stomatal density were observed in CSSL-1, CSSLs-3-5, CSSLs-8-11, CSSLs17-18, which carried DT-QTL from chromosome 1 , 3,4 , and 9 of DH212. It was recently reported that the drought-sensitive wheat cultivar Kukri had lowest stomatal density and highest water loss rate compared to the other four more tolerant genotypes $^{33}$. The literature has unravelled that greater stomatal density and smaller stomatal size is a form of adaptations to drought because it enables plants to govern water transport and transpiration more effectively ${ }^{18}$.

In our study, high correlations were detected among the quantitative studied traits. LW showed a negative correlation to $W_{\text {SUE }}$. In contrast, LW was positively correlated with $N_{\mathrm{LVB}}, N_{\mathrm{SVB}}$, and $N_{\mathrm{TVB}}$, which was well supported by other studies ${ }^{34}$. Similarly, $N_{\text {TVB }}$ was positively correlated with $A_{\text {TXY }}$ and bulliform cells dimensions. Again, $T_{\mathrm{L}}$ exhibited a positive correlation with $L_{\mathrm{VLR}}, L_{\mathrm{HLR}}$, and $A_{\mathrm{TXY}}$, which agreed with an earlier study which elucidated that thicker veins are a typical character found in larger leaves ${ }^{35}$. Furthermore, it has been documented that larger leaves tend to have larger petioles and major veins, which contain more numerous and larger xylem and phloem conduits, allowing transport capacity per unit leaf area to be independent of leaf size $^{24}$. In another study, thick leaves were found to be supported by veins with wider diameter as in $O$. coarctata and $O$. australiensis whereas thin leaves were supported by narrow veins as seen in the leaves of $O$. ridleyi, O. granulata, and O. punctata ${ }^{34}$.

Our results showed differences between CSSLs and their parent lines in the distance between adjacent large vascular bundles, with CSSL-12 and CT9993 sharing similarities in the distance between 
large and small vascular bundles. The findings obtained in our study suggested that drought-tolerant rice lines appeared to have long distance between adjacent large vascular bundles. This finding is inconsistent with an earlier study which documented that the mean interveinal distance in $\mathrm{C}_{4}$ plants $(120 \mu \mathrm{m})$ was considerably less than that observed in $\mathrm{C}_{3}$ plants $(280 \mu \mathrm{m})$, and that these lower interveinal distance values were correlated to a decrease in mesophyll/bundle sheath tissue ratio ${ }^{36}$. Furthermore, a different study supported that the leaves of $\mathrm{C}_{4}$ grasses tend to develop transverse veins more densely than do those of $\mathrm{C}_{3}$ grasses, and demonstrated that the shift in vein density in $\mathrm{C}_{4}$ grasses is related to increased minor and cross veins, rather than major veins ${ }^{37}$.

Our results also showed that lower ratios of large/small vascular bundles were observed for CSSLs, as compared to KDML105. Similarly, the average number of large vascular bundles per leaf was lower in CSSLs than in KDML105 and droughttolerant lines. In contrast, the total number of vascular bundles and small vascular bundles per leaf were greater in CSSLs than in KDML105. Our findings suggested that high total number of vascular bundles is a unique character in droughttolerant rice plants, which was supported by an earlier study ${ }^{22}$.

According to PCA plots, the studied rice lines fell into seven non-overlapping groups. Some scattering was detected, representing intraspecific variation in the quantitative traits such as leaf thickness, length of lateral ridge, vertical length of lateral vascular bundle, bulliform cell depth, bulliform cell width, number of large vascular bundles and total area of xylem vessels. It is interesting to note that the drought-tolerant standard check CT9993 was clearly isolated from the others, which might be due to its outstanding characters. It is also astonishing that CSSL-9 which shared major similarities of quantitative traits to CT9993 fell outside its CSSL group. Parental lines, DH103, DH212 and KDML105, were clearly differentiated from the CSSL group. Notably, the drought-tolerant standard check IR62266 was loosely grouped into the major group of CSSLs. It was noted that CSSLs 14-16 carrying DT-QTL on chromosome 8 were tightly grouped. Furthermore, CSSLs 3 and 4 carrying DT-QTL on chromosome 1 were also tightly clustered.

Drought responses of this set of CSSLs have been reported previously ${ }^{38}$. The 20 CSSLs were grown in pots containing $40 \mathrm{~kg}$ of water saturated soils until the plants were 30 days old, after which the water was drained and the soils were left to dry out for 40 days. Based on leaf rolling scores, leaf water potential and relative water content, large variation in drought responses were observed among the 20 CSSLs. Based on leaf water status under stress, CSSL-9 appeared to be more drought sensitive, while CSSL-4 more tolerant, than the remaining CSSLs. Despite its close similarity in leaf anatomy to the drought-tolerant standard cultivars, CSSL-9 appeared to have lower ability to conserve water, in this pot experiment, because the extensive root growth in response to drought rapidly depleted soil water. In contrast, a field study revealed that CSSL-6, -9, -10, and -15 had lower yield reduction than KDML105 associated with better root adaptation traits such as root length, root surface area, root diameter and root volume ${ }^{39}$. Hence the ability to withstand water stress is related to both leaf and root traits. The ability of the roots to uptake water from deeper soil layers as well as the adaptive leaf anatomical characteristics which enable efficient water conductivity and water status maintenance are considered the main features contributing to drought adaptation of some of the CSSLs under study.

\section{CONCLUSIONS}

This study has highlighted variations in quantitative traits in leaf anatomical characteristics in 25 rice lines, including 4 drought-tolerant parent lines (DH103, DH212, CT9993 and IR62266), 20 CSSLs and the drought-sensitive recurrent parent, KDML105. All 4 drought-tolerant parent lines and all or almost all 20 CSSLs showed greater LW, $N_{\mathrm{SVB}}$, $N_{\text {TVB }}, D_{\text {SLE }}$, and shorter $L_{\text {SUE }}$ than KDML105. Our results suggest that multiple leaf anatomical traits including leaf width and thickness, number and size of vascular bundles, stomatal density and size may be used as indicators for selecting rice lines for drought tolerance.

Acknowledgements: This work was supported by grants from the National Science and Technology Development Agency (NSTDA) under the Thailand Graduate Institute of Science and Technology (TGIST), (Grant No. TG-CPMO-22-12-56-002D), and the Salttolerant Rice Research Group, Khon Kaen University. The authors would like to thank the Faculty of Agriculture of Khon Kaen University for kindly providing the greenhouse space. 


\section{REFERENCES}

1. Pandey S, Bhandari H, Hardy B (2007) Economic Costs of Drought and Rice Farmers' Coping Mechanisms: a Cross-country Comparative Analysis, International Rice Research Institute, Los Baños, Philippines.

2. Farooq M, Wahid A, Kobayashi N, Fujita D, Basra SMA (2009) Plant drought stress: effects mechanisms and management. Agron Sustain Dev 29, 185-212.

3. Purushothaman R, Zaman-Allah M, Mallikarjuna N, Pannirselvam R, Krishnamurthy L, Gowda CLL (2013) Root anatomical traits and their possible contribution to drought tolerance in grain legumes. Plant Prod Sci 16, 1-8.

4. Olsen JT, Caudle KL, Johnson LC, Baer SG, Maricle BR (2013) Environmental and genetic variation in leaf anatomy among populations of Andropogon gerardii (Poaceae) along a precipitation gradient. $A m$ $J$ Bot 100, 1957-68.

5. Chakhchar A, Wahbi S, Lamaoui M, Ferradous A, El Mousadik A, Ibnsouda-Koraichi S, Filali-Maltouf A, El Modafar C (2015) Physiological and biochemical traits of drought tolerance in Argania spinosa. J Plant Interact 10, 252-61.

6. Hadebe ST, Modi AT, Mabhaudhi T (2017) Drought tolerance and water use of cereal crops: a focus on sorghum as a food security crop in sub-Saharan Africa. J Agron Crop Sci 203, 177-91.

7. Zhang F-J, Zhang K-K, Du C-Z, Li J, Xing Y-X, Yang L-T, Li Y-R (2015) Effect of drought stress on anatomical structure and chloroplast ultrastructure in leaves of sugarcane. Sugar Tech 17, 41-8.

8. Sibounheuang V, Basnayake J, Fukai S (2006) Genotypic consistency in the expression of leaf water potential in rice (O. sativa). Field Crop Res 97, 142-54.

9. Martins MBG, Zieri R (2003) Leaf anatomy of rubbertree clones. Sci Agr 60, 709-13.

10. Huang L, Zhang F, Zhang F, Wang W, Zhou Y, Fu B, Li Z (2014) Comparative transcriptome sequencing of tolerant rice introgression line and its parents in response to drought stress. BMC Genom 15, 1026-16.

11. Kumar A, Dixit S, Ram T, Yadaw RB, Mishra KK, Mandal NP (2014) Breeding high-yielding droughttolerant rice: genetic variations and conventional and molecular approaches. $J$ Exp Bot 65, 6265-78.

12. Kanjoo V, Punyawaew K, Siangliw JL, Jearakongman S, Vanavichit A, Toojinda T (2012) Evaluation of agronomic traits in chromosome segment substitution lines of KDML105 containing drought tolerance QTL under drought stress. Rice Sci 19, 117-24.

13. Siangliw JL, Jongdee B, Pantuwan G, Toojinda T (2007) Developing KDML105 backcross introgression lines using marker-assisted selection for QTLs associated with drought tolerance in rice. Sci Asia 33, 207-14.

14. Kanjoo V (2012) Development of chromosome seg- ment substitution lines related to drought tolerance in rice. $\mathrm{PhD}$ thesis, Kasetsart Univ.

15. Johansen DA (1940) Plant Microtechnique, McGrawHill, New York.

16. Wankhade SD, Bahaji A, Mateu-Andrés I, Cornejo MJ (2010) Phenotypic indicators of $\mathrm{NaCl}$ tolerance levels in rice seedlings: variations in development and leaf anatomy. Acta Physiol Plant 32, 1161-9.

17. Lawson T, Blatt MR (2014) Stomatal size, speed, and responsiveness impact on photosynthesis and water use efficiency. Plant Physiol 164, 1556-70.

18. Luković J, Maksimović I, Zorić L, Nagl N, Perčić M, Polić D, Putnik-Delić M (2009) Histological characteristics of sugar beet leaves potentially linked to drought tolerance. Ind Crop Prod 30, 281-6.

19. Farooq M, Kobayashi N, Ito O, Wahid A, Serraj R (2010) Broader leaves result in better performance of indica rice under drought stress. $J$ Plant Physiol 167, 1066-75.

20. Wang L-F, Chen Y-Y (2013) Characterization of a wide leaf mutant of rice $O$. sativa with high yield potential in field. Pakistan $J$ Bot 45, 927-32.

21. Yue B, Xue WY, Luo LJ, Xing YZ (2006) QTL analysis for flag leaf characteristics and their relationships with yield and yield traits in rice. Acta Genetica Sin 33, 824-32.

22. Sage RF, McKown $A D$ (2006) Is $C_{4}$ photosynthesis less phenotypically plastic than $\mathrm{C}_{3}$ photosynthesis? $J$ Exp Bot 57, 303-17.

23. Jacobsen AL, Agenbag L, Esler KJ, Pratt RB, Ewers FW, Davis SD (2007) Xylem density biomechanics and anatomical traits correlate with water stress in 17 evergreen shrub species of the Mediterraneantype climate region of South Africa. J Ecol 95, 171-83.

24. McKown AD, Cochard H, Sack L (2010) Decoding leaf hydraulics with a spatially explicit model: principles of venation architecture and implications for its evolution. Am Nat 175, 447-60.

25. Feldman $A B$, Leung $H$, Baraoidan $M$, ElmidoMabilangan A, Canicosa I, Quick WP, Sheehy J, Murchie EH (2017) Increasing leaf vein density via mutagenesis in rice results in an enhanced rate of photosynthesis, smaller cell sizes and can reduce interveinal mesophyll cell number. Front Plant Sci 8, $1-10$.

26. White JW, Montes-R C (2005) Variation in parameters related to leaf thickness in common bean (Phaseolus vulgaris L.). Field Crop Res 91, 7-21.

27. Liu C-G, Zhou X-Q, Chen D-G, Li LJ, Li JC, Chen YD (2014) Natural variation of leaf thickness and its association to yield traits in indica rice. J Integr Agr 13, 316-25.

28. Wang R, Huang W, Chen L, Ma L, Guo C, Liu X (2011) Anatomical and physiological plasticity in Leymus chinensis (Poaceae) along large-scale longitudinal gradient in northeast China. PLoS One 6, 1-8. 
29. Wu L-L, Liu Z-L, Wang J-M, Zhou C-Y, Chen K-M (2011) Morphological, anatomical, and physiological characteristics involved in development of the large culm trait in rice. Aust J Crop Sci 5, 1356-63.

30. Kulkarni M, Schneider B, Raveh E, Tel-Zur N (2010) Leaf anatomical characteristics and physiological responses to short-term drought in Ziziphus mauritiana (Lamk.). Sci Hort 124, 316-22.

31. Kondo M, Aguilar A, Abe J, Morita S (2000) Anatomy of nodal roots in tropical upland and lowland rice varieties. Plant Prod Sci 3, 437-55.

32. Wang Y, Xi Chen X, Xiang CB (2007) Stomatal density and bio-water saving. J Integr Plant Biol 49, 1435-44.

33. Bi H, Kovalchuk N, Langridge P, Tricker PJ, Lopato S, Borisjuk N (2017) The impact of drought on wheat leaf cuticle properties. BMC Plant Biol 17, 85-97.

34. Chatterjee J, Dionora J, Elmido-Mabilangan A, Wanchana S, Thakur V, Bandyopadhyay A, Brar DS, Quick WP (2016) The evolutionary basis of naturally diverse rice leaves anatomy. PLoS One 11, 1-25.

35. Sack L, Scoffoni C, McKown AD, Frole K, Rawls M, Havran JC, Tran H, Thusuong T (2012) Developmentally based scaling of leaf venation architecture explains global ecological patterns. Nat Comm 3, $1-10$.

36. Ogle K (2003) Implications of interveinal distance for quantum yield in $\mathrm{C}_{4}$ grasses: a modelling and metaanalysis. Oecologia 136, 532-42.

37. Ueno O, Kawano Y, Wakayama M, Takeda T (2006) Leaf vascular systems in $\mathrm{C}_{3}$ and $\mathrm{C}_{4}$ grasses: a twodimensional analysis. Ann Bot 97, 611-21.

38. Larkunthod P (2015) Osmotic adjustment of Khao Dawk Mali 105 chromosome segment substitution lines (CSSL) carrying drought tolerant QTLs under water deficit conditions. MSc thesis, Khon Kaen Univ.

39. Pinta W, Vorasoot N, Jongrungklang N, Saingliw JL, Toojinda T, Sanitchon J (2017) Evaluation of Khao Dawk Mali 105 chromosome segment substitution lines possessing various drought tolerance QTLs under drought stress. Sabrao J Breed Genet 49, 368-86. 